\title{
HUBUNGAN FREKUENSI KUNJUNGAN ANC (Ante Natal Care) DENGAN RIWAYAT PEMBERIAN ASI PADA BAYI USIA 6 BULAN
}

\author{
Maria Pangkrasia Kirimunun, Etika Ratna Noer ${ }^{*}$ \\ Program Studi Ilmu Gizi Fakultas Kedokteran Universitas Diponegoro \\ J1.Dr.Sutomo No.18, Semarang, Telp (024) 8453708, Email : gizifk@ undip.ac.id
}

\begin{abstract}
Background: Breastfeeding is beneficial to the health of the baby. But when the practice is still low. Health Research Data (Riskesdas) 2010 show, infants received exclusive breastfeeding in Indonesia only 15.3\%. The main problem of the low exclusive breastfeeding in Indonesia is a socio-cultural factors and lack of knowledge of pregnant women, families and communities.

Objective: The study aimed to observed association between ANC visit frequency with a history of breastfeeding in infants aged 6 months in Puskesmas Mopah Merauke Regency, Papua Province.

Methods: Observational analytic study with cross-sectional design and the subject is lactating mothers. Subject characteristic, frequency of ANC visits and breast feeding history were acquired using questionnaire. Data were analyzed quantitative and using chi square test.

Results: Result univariat showed the frequency of ANC visits has no significant relationship with a history of breast feeding in infants aged 6 months $(p=0,713)$. Knowledge and culture still supporting the cause of the mother for not doing exclusive breastfeeding.

Conclusion: Frequency of ANC visits was not associated with a history of breast feeding in infanfts aged 6 bulan.

Keywords: ANC visits; Breastfeeding
\end{abstract}

\begin{abstract}
ABSTRAK
Latar Belakang: ASI bermanfaat untuk kesehatan bayi. Namun saat praktiknya masih rendah. Data Riset Kesehatan Dasar (Riskesdas) 2010 menunjukkan, bayi yang mendapatkan ASI Eksklusif di Indonesia hanya 15,3\%. Penyebab rendahnya pemberian ASI Eksklusif di Indonesia adalah faktor sosial budaya dan kurangnya pengetahuan ibu hamil, keluarga dan masyarakat.

Tujuan: Mengetahui hubungan frekuensi kunjungan ANC (Ante Natal Care) dengan riwayat pemberian ASI pada bayi usia 6 bulan di wilayah kerja Puskesmas Mopah Kabupaten Merauke, Propinsi Papua.

Metode: Penelitian observasional analitik dengan desain cross sectional dan subjek adalah ibu menyusui. Data karakteristik subjek, frekuensi kunjungan ANC dan riwayat pemberian ASI diperoleh melalui kuesioner. Subjek sebanyak 30 ibu diperoleh dengan cara purposive sampling. Data dianalisis secara kuantitatif dan menggunakan uji chi square.

Hasil: Hasil univariat menunjukkan frekuensi kunjungan ANC tidak mempunyai hubungan yang bermakna dengan riwayat pemberian ASI pada bayi usia 6 bulan $(p=0,713)$. Pengetahuan dan budaya merupakan penyebab yang masih mendukung ibu untuk tidak melakukan pemberian ASI Eksklusif.

Simpulan: Frekuensi kunjungan ANC tidak berhubungan dengan riwayat pemberian ASI pada bayi usia 6 bulan.

Kata kunci: Kunjungan ANC; Pemberian ASI
\end{abstract}

\section{PENDAHULUAN}

Sasaran target Millenium Development Goals (MDGs) salah satunya adalah penurunan angka kematian bayi (AKB). Menurut Survei Demografi Kesehatan Indonesia (SDKI) tahun 2007, AKB sebesar 34 per 1000 kelahiran hidup. ${ }^{1}$ Usaha agar mencapai target penurunan $\mathrm{AKB}$, dapat dilakukan dengan cara memberi dukungan kepada para ibu dalam melaksanakan pemberian ASI secara eksklusif, imunisasi, pemeriksaan kehamilan (kunjungan ANC), dan kunjungan bayi secara teratur. ${ }^{2}$ Pemberian ASI Eksklusif dapat menekan AKB sebesar 30.000 kematian bayi di Indonesia dan 10 juta kematian bayi di dunia. ${ }^{3}$
Hal ini tampak bahwa pemberian ASI Eksklusif seperti yang direkomendasikan WHO, masih jarang diprektekkan oleh ibu menyusui di berbagai negara, karena berbagai faktor, seperti sosial, budaya, ekonomi, dan politik. ${ }^{5}$ Diperkirakan $85 \%$ ibu-ibu di dunia tidak memberikan ASI secara optimal, karena praktek pemberian ASI telah berubah seiring dengan banyaknya informasi yang tersedia lewat media massa. ${ }^{4}$

Pemberian ASI Eksklusif di Indonesia masih tergolong rendah, ditunjukkan oleh data Riset Kesehatan Dasar (Riskesdas) tahun 2010 bahwa jumlah bayi yang mendapatkan ASI Eksklusif sampai usia 6 bulan hanya sebesar 15,3\%. ${ }^{6} \mathrm{Hal}$ tersebut tidak jauh berbeda dengan yang terjadi di 
wilayah kerja Puskesmas Mopah Kabupaten Merauke Papua, sampai dengan tahun 2013 menunjukkan cakupan pemberian ASI Eksklusif sekitar $17,2 \% .^{7}$

Rendahnya jumlah pemberian ASI Eksklusif disebabkan karena timbulnya berbagai masalah yaitu kurangnya informasi dan pemahaman ibu bahkan petugas kesehatan sekalipun tentang manfaat dan pentingnya pemberian ASI Eksklusif, serta adanya masalah pada ibu maupun pada bayi. ${ }^{8}$ Salah satu upaya meningkatkan keberhasilan pemberian ASI Eksklusif secara baik dan benar adalah melalui program Kesehatan Ibu dan Anak (KIA) yang pelaksanaannya bersamaan dengan Ante Natal Care (ANC), ketika seorang ibu hamil melakukan kunjungan $A N C$, ibu tersebut akan mendapatkan pendidikan atau penyuluhan dan informasi tentang kesehatan dan gizi termasuk informasi persiapan pemberian ASI dengan menyusui secara dini dengan posisi yang benar, teratur dan eksklusif. ${ }^{9}$

Kunjungan Ante Natal Care (ANC) merupakan pelayanan penting untuk memastikan kesehatan ibu selama kehamilan dan menjamin ibu untuk melakukan persalinan di fasilitas kesehatan agar berjalan dengan baik dan normal, serta mendukung persiapan pemberian ASI secara eksklusif, guna membantu pemerintah dalam mencapai penurunan Angka Kematian Bayi (AKB) di Indonesia. Para ibu yang tidak melakukan kunjungan ante natal cenderung bersalin di rumah $(86,7 \%)$ dibandingkan dengan ibu yang melakukan empat kali kunjungan ante natal atau lebih $(45,2 \%) .{ }^{10}$ Setiap ibu hamil seharusnya mendapat perawatan kehamilannya secara baik, dengan cara memeriksakan kehamilannya, tetapi pada kenyataannya masih banyak ibu hamil belum mengerti yang lebih dalam tentang pemeriksaan kehamilan (ante natal care).

Cakupan pemberian ASI Eksklusif dan cakupan kunjungan ANC di wilayah kerja Puskesmas Mopah Kabupaten Merauke, masih dibawah target rencana strategi provinsi Papua, yakni $100 \%$ baik cakupan pemberian ASI Eksklusif dan cakupan kunjungan $A N C .{ }^{11}$ Masih banyak ibuibu yang kurang menyadari pentingnya pemeriksaan kehamilan sehingga menyebabkan tidak terdeteksinya faktor-faktor risiko tinggi yang mungkin dialami oleh ibu hamil tersebut dan akan berlanjut pada persiapan pemberian ASI Eksklusif. Dari data cakupan kunjungan ante natal care masih tergolong rendah yaitu $50,65 \%$, karena masih erat hubungannya dengan kemiskinan, pendidikan ibu, faktor geografis dan adanya pembangunan sosial. Kaum ibu yang miskin dan tidak berpendidikan mengalami kesulitan dalam melakukan kunjungan ke fasilitas pelayanan kesehatan karena keterbatasan biaya dan ketidaktahuan.

Dari survei awal yang dilakukan di Puskesmas Mopah pada bulan desember 2013, hasil kunjungan $A N C$ dan pemberian ASI Eksklusif belum dapat mencapai hasil yang maksimal. Ibu-ibu di wilayah kerja Puskesmas Mopah masih belum mengetahui dan memahami benar tentang tujuan daripada ante natal care. Hal ini bisa menjadi salah satu penyebab dari masih rendahnya pemberian ASI Eksklusif, karena dalam ANC akan diberikan suatu pelayanan kesehatan dengan mutu yang baik sekaligus merupakan tempat untuk mendapatkan penyuluhan, konseling gizi/informasi gizi dalam membantu ibu menjaga kesehatan selama masa kehamilan dan mempersiapkan diri ibu untuk pemberian ASI secara eksklusif saat ibu hamil melakukan kunjungan $A N C$.

Berdasarkan latar belakang maka dilakukan penelitian hubungan frekuensi kunjungan ANC (Ante Natal Care) dengan riwayat pemberian ASI pada bayi usia 6 bulan.

\section{METODE}

Penelitian dilaksanakan di Wilayah Kerja Puskesmas Mopah Kabupaten Merauke, Papua. Penelitian ini termasuk penelitian observasional analitik dengan desain cross sectional.

Pengambilan subjek menggunakan metode purposive sampling, berdasarkan kriteria inklusi yaitu ibu yang mempunyai bayi usia 6 bulan yang memberikan ASI diambil secara keseluruhan. Responden yang terpilih kemudian harus mengisi persetujuan Informed Consent sebagai tanda bahwa responden bersedia mengikuti penelitian ini. Kriteria eksklusi dalam penelitian ini adalah subjek dalam keadaan sakit dan pindah domisili selama penelitian.

Pemilihan responden dimulai dengan pencarian data ibu yang memiliki bayi usia 6 bulan yang mendapat ASI dari data register laporan posyandu di Puskesmas. Setelah mendapatkan data yang sesuai dengan kriteria penelitian sebanyak 30 responden, maka peneliti menentukkan jadwal pelaksanaan pengumpulan data. Selanjutnya mendatangi lokasi penelitian yang bersamaan dengan jadwal kegiatan posyandu saat dilakukan, untuk pelaksanaan wawancara mendalam secara langsung lewat kuesioner dan observasi dengan subjek penelitian.

Pengumpulan data dilakukan dengan observasi, wawancara mendalam (in depth interview) pada saat kegiatan posyandu berlangsung di masing-masing posyandu. Pengamatan langsung 
dan wawancara mendalam melalui kuesioner dilakukan untuk mengetahui lebih dalam tentang frekuensi kunjungan $A N C$ sesuai standar minimal $\geq 4$ kali selama 3 Trimester, yaitu 1 kali saat Trimester I, 1 kali saat Trimester II dan 2 kali saat Trimester III. Riwayat pemberian ASI yaitu ASI Eksklusif adalah pemberian ASI saja sampai bayi berumur 6 bulan dan ASI Non Eksklusif adalah pemberian ASI kurang dari 6 bulan. Wawancara mendalam lewat kuesioner ini dilakukan 1 kali pada saat kegiatan posyandu.

Analisis data yang digunakan adalah analisis kuantitatif dan dalam penyajiannya menggunakan tabel distribusi frekuensi berdasarkan dari data yang terkumpul kemudian disimpulkan. Data kuantitatif diolah sesuai variabel yang tercakup dalam penelitian dengan metode deduksi yaitu metode penarikan kesimpulan dari hal-hal umum ke hal-hal yang khusus. Selanjutnya pelaporan disajikan gambaran secara deskriptif.

Data yang dikumpulkan dalam penelitian ini adalah karakteristik subjek meliputi; usia, pendidikan, pekerjaan, data frekuensi kunjungan $A N C$ dan data riwayat pemberian ASI Eksklusif. Data yang telah diperoleh kemudian diolah dan dianalisis dengan program komputer. Analisis univariat dilakukan untuk mengidentifikasi data karakteristik subjek, seperti umur, pendidikan dan pekerjaan. Analisis bivariat dilakukan dengan uji Chi Square.

\section{HASIL \\ Karakteristik Responden}

Karakteristik responden yang diamati meliputi umur, pendidikan dan pekerjaan.Distribusi responden menurut kelompok ini dapat dilihat pada tabel 1.Umur responden bervariasi mulai dari 19-45 tahun. Kelompok umur responden 21-35 tahun merupakan kelompok umur tertinggi yaitu sebesar $60,0 \%$. Sebagian besar responden telah menamatkan pendidikan dasar sembilan tahun yaitu SMP/SLTP. Sebagian besar responden adalah tidak bekerja atau sebagai ibu rumah tangga (IRT) yaitu sebesar $96,7 \%$

Tabel 1. Distribusi Karakteristik Subjek Penelitian

\begin{tabular}{lrr}
\hline Karakteristik & Jumlah (orang) & Persen (\%) \\
\hline Usia & & \\
$<21$ Tahun & 5 & 16,7 \\
$21-35$ & 18 & 60 \\
$>35$ & 7 & 23,3 \\
Pendidikan & & \\
$\quad$ Tidak Sekolah & 2 & 6,7 \\
SD & 4 & 13,3 \\
SMP/SLTP & 8 & 26,7 \\
SMU/SLTA & 10 & 33,3 \\
PT & 6 & 20,0 \\
Pekerjaan & & \\
Bekerja & 1 & 3,3 \\
Tidak Bekerja & 29 & 96,7 \\
\hline
\end{tabular}

\section{Frekuensi Kunjungan ANC}

Frekuensi kunjungan $A N C$ ditampilkan untuk mengetahui jumlah kunjungan $A N C$ yang dilakukan oleh responden selama kehamilannya, dapat dilihat pada table 2 .

Tabel 2. Distribusi Frekuensi Kunjungan $A N C$

\begin{tabular}{lcc}
\hline Frekuensi Kunjungan ANC & Jumlah ( orang ) & Persen (\%) \\
\hline Tidak Terpenuhi & 15 & 50 \\
Terpenuhi & 15 & 50 \\
\hline & & 100 \\
\hline
\end{tabular}


Tabel 2, menunjukkan bahwa frekuensi kunjungan ANC seluruh responden 50\% terpenuhi.

\section{Riwayat Pemberian ASI}

Riwayat pemberian ASI digunakan untuk mengetahui apakah bayi diberikan ASI oleh ibu semua eksklusif atau tidak, dapat dilihat pada table 3.

Tabel 3. Distribusi Riwayat Pemberian ASI

\begin{tabular}{lcc}
\hline Riwayat Pemberian ASI & Jumlah( orang) & Persen (\%) \\
\hline ASI Non Eksklusif & 13 & 43,3 \\
ASI Eksklusif & 17 & 56,7 \\
& & \\
\hline Total & 30 & 100 \\
\hline
\end{tabular}

Tabel 3, menunjukkan bahwa jumlah Hubungan Frekuensi Kunjungan ANC dengan responden mempunyai riwayat pemberian ASI Riwayat Pemberian ASI Eksklusif sebesar 56,7\%.

Tabel 4. Hubungan Frekuensi Kunjungan ANC dengan Riwayat Pemberian ASI

\begin{tabular}{llllll}
\hline & & \multicolumn{2}{c}{ Riwayat Pemberian ASI } & P \\
& & Non Eksklusif & Eksklusif & & value \\
\hline $\begin{array}{l}\text { Frekuensi } \\
\begin{array}{l}\text { Kunjungan } \\
\text { ANC }\end{array}\end{array}$ & Tidak Terpenuhi & $7(46,7 \%)$ & $8(53,3 \%)$ & $15(100 \%)$ & 0,713 \\
Total & $6(40,0 \%)$ & $9(60,0 \%)$ & $15(100 \%)$ & \\
\hline
\end{tabular}

Hasil uji statistik didapatkan $\mathrm{p}=0,713$ Nilai $\mathrm{p}>\alpha(0,05)$ maka dapat disimpulkan tidak ada hubungan frekuensi kunjungan $A N C$ dengan riwayat pemberian ASI.

\section{PEMBAHASAN}

Kunjungan ANC pada responden dalam penelitian ini cukup bervariasi yaitu antara 4-10 kali kunjungan selama masa kehamilan. Persentase frekuensi kunjungan $A N C$ antara terpenuhi dan tidak terpenuhi adalah sama yaitu 50\%. Tetapi ada beberapa alasan dari ibu yang frekuensi kunjungan $A N C$ tidak terpenuhi yaitu: lupa, malas, adanya kesibukan lain, tidak dapat informasi dan takut nanti bayinya kenapa-kenapa lagi saat diperiksa. Hasil ini tidak terlalu beda jauh dengan data persentase yang diambil dari Puskesmas Mopah Merauke yaitu sebesar $60,5 \%$.

Ante Natal Care merupakan program pelayanan terencana yang didalamnya berupa observasi, edukasi dan penanganan medik pada ibu hamil untuk memperoleh proses pemeriksaan kehamilan dan persalinan yang aman dan memuaskan. Selain itu salah satu dari tujuan pelayanan $A N C$ (WHO) yaitu pemeliharaan dan pemberian manajemen laktasi yang mencakup nasihat dan petunjuk yang berkaitan dengan kehamilan, persalinan, kala nifas, laktasi (pemberian ASI Eksklusif) dan aspek keluarga berencana. ${ }^{12}$

Berdasarkan hasil analisis univariat dari penelitian ini menunjukkan bahwa frekuensi kunjungan $A N C$ tidak mempunyai hubungan yang bermakna dengan riwayat pemberian ASI pada bayi usia 6 bulan. Jumlah persentase pemberian ASI Eksklusif sebanyak 56,7\%. Bila dibandingkan dengan target cakupan ASI Eksklusif yang terdapat dalam Rencana Strategi Dinas Kesehatan Propinsi Papua, angka ini masih jauh dari harapan yaitu $100 \%$, dengan kata lain pemberian ASI secara eksklusif masih sangat rendah. Hal ini masih disebabkan oleh faktor pengetahuan dan budaya modernisasi penggunaan susu formula, dan adapun alasan lain yaitu; ASI kurang, rasa ASI hambar, bayi masih lapar, sudah isap-isap jari, puting susu lecet dan adanya kesibukan ibu.

Hasil penelitian ini menunjukkan pengetahuan dan budaya modernisasi penggunaan susu formula yang masih menyebabkan rendahnya pemberian ASI Eksklusif, tetapi dengan melihat 
secara langsung masih kurangnya peran tenaga kesehatan (bidan dan petugas gizi puskesmas) untuk memberikan penyuluhan kesehatan terutama tentang ASI Eksklusif dan menyusui lebih intensif yang dilakukan di posyandu. Penyuluhan dilakukan dengan cara konseling khusus dengan sasaran hanya ibu menyusui. Namun kegiatan tersebut tidak dilakukan pada ibu hamil. Kegiatan penyuluhan ini seharusnya dapat dilaksanakan pada saat pemeriksaan $A N C$, dimana ibu diberikan informasi tentang menyusui dan manfaat ASI Eksklusif. Hal ini menunjukkan bahwa tenaga kesehatan dalam hal ini bidan dan tenaga gizi belum maksimal dalam mensosialisasikan 10 Langkah Menuju Keberhasilan Menyusui (LKMM) terutama langkah ke-3 hingga ke-9.

“Kotak Wawancara Mendalam Singkat Pada Responden"

Alasan no 1.

'......Saya tidak bisa memberi ASI dengan baik karena kurang, makanya saya berikan susu formula lagi......"

Wawancara mendalam

SP 3. 45 thn. SMP \& SP 5. 37 thn. SMU

Alasan no.2.

“...... Anak saya selalu menolak waktu saya memberikan ASI, mungkin air susu saya tidak ada rasanya ya (hambar), jadi saya terpaksa beri susu botol......"

Wawancara mendalam

SP 23. 20 thn. SMP \& SP 22. 35 thn. SMP

Alasan no.3

“......Masih menangis lagi setalah saya beri ASI mungkin masih lapar, terus saya coba beri bubur campur, ya anak saya makan dengan lahap, akhirnya tidak menangis lagi..... "

Wawancara mendalam

SP 18. 35 thn. SMU, SP 29. 19 thn. SMP \& SP 16. 26 thn. SD

Alasan no.4

“......Karena sudah isap-isap jari, mungkin anak saya mau makan, jadi saya langsung berikan bubur SUN......"

Wawancara mendalam

SP 24. 25 tahun. PT

Alasan no.5

“......Puting susu saya lecet, jadi saya tidak bisa melanjutkan pemberian ASI pada anak saya, dan saya menambahkan dengan susu formula ......"

Wawancara mendalam

Alasan no.6

SP 21.28 thn. PT \& SP 19. 22 thn. SMU

“......Banyak kesibukan rumah tangga, sehingga saya suka lupa memberikan ASI, dan satu-satunya jalan saya beri susu botol saja......”

Wawancara mendalam

SP 12. 35 thn. SMP, SP 13. 35 thn. SMP, SP 17. 28 thn. Tidak Sekolah

Berdasarkan wawancara mendalam singkat terhadap responden/ibu menyusui ini, bahwa dapat dikatakan peran petugas kesehatan yaitu bidan dan tenaga gizi puskesmas masih kurang dalam memberikan penyuluhan dan informasi tentang ASI Eksklusif saat $A N C$ dilakukan oleh ibu selama masa kehamilannya. Hal ini dapat menjadi penyebab rendahnya pengetahuan ibu tentang menyusui dan pemberian ASI Eksklusif setelah ibu melahirkan.

Menyusui adalah suatu proses yang alamiah. Hampir semua ibu di dunia berhasil menyusui bayinya tanpa pernah membaca dan mempelajari buku tentang ASI. Bahkan ibu yang buta huruf pun dapat menyusui anaknya dengan baik. Namun pada kenyataannya tidaklah selalu mudah untuk melakukan hal yang alamiah dalam lingkungan kebudayaan kita saat ini. Meskipun kampanye pemberian ASI eksklusif sudah dimulai sejak tahun 1990 dengan dikeluarkannya Deklarasi Innocent, dan bertujuan untuk melindungi, mempromosikan, dan memberi dukungan pada pemberian ASI, namun jumlah ibu yang memberikan ASI secara eksklusif pada bayinya masih termasuk rendah. Deklarasi yang juga ditandatangani Indonesia ini memuat hal-hal sebagai; "tujuan global untuk meningkatkan kesehatan dan mutu makanan bayi secara optimal maka semua ibu dapat memberikan ASI Eksklusif dan semua bayi diberi ASI Eksklusif 
sejak lahir sampai berusia 4-6 bulan. Setelah berumur 4-6 bulan, bayi diberi makanan pendamping/padat yang benar dan tepat, sedangkan ASI tetap diteruskan sampai usia 2 tahun atau lebih. ${ }^{13}$

Sebagian (43,3\%) subjek yang tidak memberikan ASI secara eksklusif masih belum mengetahui tentang manfaat ASI Eksklusif. Mereka umumnya pernah mendengar tapi tidak mengerti maksudnya. Ada juga yang pernah membaca buku KIA tapi lupa. Pengetahuan ibu yang kurang tentang ASI Eksklusif inilah, bisa mennyebabkan gagalnya pemberian ASI secara eksklusif. Selama mereka tidak tahu maka merekapun tidak akan pernah melaksanakannya. Jadi dapat disimpulkan bahwa subjek memiliki tingkat pengetahuan tentang ASI hanya sebatas pernah mendengar atau masih kurang.

Pengetahuan ibu tentang ASI Eksklusif dalam penelitian ini masih sebatas "tahu bahwa" sehingga mereka tidak begitu paham secara mendalam dan tidak memiliki keterampilan untuk mempraktikkannya. Dan jika pengetahuan ibu ini lebih luas serta mempunyai pengalaman tentang ASI eksklusif, maka ibu memiliki gambaran dan bahkan dapat membantu ibu dalam memberikan ASI secara eksklusif. Kurangnya pengetahuan para ibu tersebut tentang manfaat ASI ini menjadi salah satu penghambat keberlangsungan pemberian ASI.

Penelitian yang dilakukan Nurafifah (2007) yang menyatakan bahwa pengetahuan ibu tentang ASI eksklusif dapat diperoleh dari berbagai sumber informasi. Pengetahuan yang rendah tentang ASI Eksklusif karena tidak memperoleh penyuluhan intensif saat pemeriksaan kehamilan (kunjungan $A N C)$ tentang manfaat dan tujuan pemberian ASI Eksklusif. ${ }^{14}$

Pengetahuan termasuk didalamnya pengetahuan gizi, dapat diperoleh melalui pendidikan formal dan informal. Pendidikan formal diperoleh dari sekolah dengan kurikulum dan jenjang yang ditetapkan, sedangkan pendidikan informal dapat diperoleh dari seluruh aspek kehidupan. ${ }^{15}$

Pengalaman dan pendidikan wanita semenjak kecil akan mempengaruhi sikap dan penampilan mereka dalam kaitannya dengan menyusui di kemudian hari. Seorang wanita yang dalam keluarga atau lingkungan sosialnya secara teratur mempunyai kebiasaan menyusui atau sering melihat wanita lain yang menyusui bayinya secara teratur, akan mempunyai pandangan yang positif tentang pemberian ASI. Di daerah yang mempunyai "budaya susu formula / botol", gadis dan wanita muda di daerah tersebut tidak mempunyai sikap positif terhadap menyusui, sesuai dengan pengalaman sehari-hari. Tidak mengherankan bila wanita dewasa dalam lingkunganini hanya memiliki sedikit bahkan tidak memiliki sama sekali informasi, pengalaman cara menyusui, dan keyakinan akan kemampuannya menyusui. ${ }^{16}$

Dalam situasi ini subjek yang kurang pengetahuannya tentang ASI Eksklusif, pada saat yang sama ia memiliki pengetahuan budaya lokal berupa ideologi makanan untuk bayi. Pengetahuan budaya lokal ini dapat disebut sebagai pengetahuan tentang ASI non-Eksklusif, yang jelas merupakan faktor penghambat bagi praktik pemberian ASI Eksklusif. ${ }^{14}$

\section{SIMPULAN}

Tidak ada hubungan antara frekuensi kunjungan $A N C$ dengan riwayat pemberian ASI pada bayi usia 6 bulan di wilayah kerja Puskesmas Mopah Kabupaten Merauke Propinsi Papua.

\section{SARAN}

Perlu dilalukan penelitian yang serupa dengan memperhatikan lokasi kegiatan penelitian, sehingga bisa memberikan gambaran yang lebih adekuat.

\section{DAFTAR PUSTAKA}

1. Kementerian Kesehatan Republik Indonesia. Profil Kesehatan Indonesia: Jakarta, 2010.

2. Depkes RI. Indikator Kesehatan Indonesia 20052009. Kementerian Kesehatan Republik Indonesia: Jakarta, 2010.

3. UNICEF. ASI Eksklusif Tekan Angka Kematian Bayi Indonesia. (http://situs.kesrepro.info/kia/agu/2006/kia03.htm diakses pada tanggal 4 Maret 2012).

4. World Health Organization. Global strategy for infant and young child feeding. WHA 55/2002/REC/I, annex 2. Geneva. World Health Organization; 2002.

5. Michael JG, Barrie M, Margetcs, John MK, Lenore A. Public Health Nutrition. Jakarta:Buku Kedokteran EGC; 2009.

6. Badan Perencanaan Pembangunan Nasional (Bappenas). Rencana Aksi Nasional Pangan dan Gizi (RANPG) 2011-2015. Jakarta: Bappenas, 2009.

7. Dinas Kesehatan Kabupaten Merauke. Laporan Program Gizi Kabupaten Merauke Tahun 2012.

8. Restuning Widiasih. Masalah-Masalah dalam Menyusui [Makalah Seminar Managemen Laktasi]; Fakultas Ilmu Keperawatan, Universitas Padjadjaran, Bandung [serial online] 2008 [cited 2012 March 14]. Available from : http://pustaka.unpad.ac.id/wp.../masalah-masalah dalam menyusui.pdf 
9. Departemen Kesehatan RI. Buku Panduan Manajemen Laktasi. Direktorat Gizi Bina Kesehatan Masyarakat; Jakarta, 2005.

10. Badan Perencanaaan Pembangunan Nasional (Bappenas). Laporan Pencapaian Tujuan Pembangunan Millenium Di Indonesia. ISBN 978979-3764-64-1. 2010

11. Data Informasi Kesehatan Provinsi Papua. Ringkasan Eksekutif Profil Kesehatan Provinsi Papua. Pusat Data dan Informasi Kementerian Kesehatan RI. Jakarta; 2011

12. Anjarwati R, Komalasari R, Adiningsih D, Yulianti D. Buku Ajar Konsep Kebidanan. Jakarta: Buku Kedokteran EGC; 2006

13. WHO dan UNICEF. Breastfeeding Counseling: A training course. Participants Manual. WHOUNICEF,New York, p. 14; 1993

14. Nur Afifah D. Faktor yang Berperan dalam Kegagalan Praktik Pemberian ASI Eksklusif. [ Tesis ] Semarang : Program Pasca Sarjana UNDIP; 2007.

15. Pranadji DK. Pendidikan Gizi (Proses Belajar Mengajar) [Diklat]. Bogor: Fakultas Pertanian, IPB.1988

16. Perinasia. Melindungi, Meningkatkan, dan Mendukung Menyusui: Peran Khusus pada Pelayanan Kesehatan Ibu Hamil dan Menyusui, Pernyataan bersama WHO/UNICEF. Jakarta: Perkumpulan Perinatologi Indonesia; 1994

17. Sudigdo S, Sofyan I. Dasar-Dasar Metodologi Penelitian Klinis. Jakarta: Bina Rupa Aksara ;1995.

18. Notoatmodjo S. Metodologi Penelitian Kesehatan. Edisi Revisi Cetakan Pertama.Jakarta:Rineka Cipta;2010.

19. Murti. Desain dan Ukuran Sampel untuk penelitian Kuantitatif dan Kualitatif di Bidang Kesehatan.Yogyakarta: Gajah madah University Press.2006.

20. Sopiyudin D. Statistika untuk Kedokteran dan Kesehatan. Jakarta: PT Arkans; 2004 